\title{
Effect of Annealing Treatment on the Anisotropy Behavior of Cold Rolled Stainless Steel 304 Sheets
}

\author{
Ahmed A. Zainulabdeen ${ }^{1}$, Jabbar H. Mohmmed ${ }^{2}$, Najmuldeen Y. Mahmood ${ }^{3}$ \\ ${ }^{1,2}$ Lecturer, Materials Engineering Department, University of Technology \\ ${ }^{3}$ Assistant Lecturer, Mechanical Engineering Department, University of Technology \\ ahmed_ameed@yahoo.com
}

\begin{abstract}
Anisotropy of materials has harmful effects during deep drawing operations and reduce it will strongly enhance the productivity and quality of deep drawing yields. In this work the effect of annealing treatment on texture and anisotropy behavior of cold rolled stainless steel 304 sheets were investigated. Uniaxial tensile test samples cut at $0 \mathrm{o}, 45 \mathrm{o}$ and $90 \mathrm{o}$ to the rolling direction were prepared in order to measure the anisotropy parameters (normal anisotropy, $r \_n$, and planar anisotropy, $\Delta \mathrm{r}$ ). Two annealing temperatures (1050, and 1150) ${ }^{\circ} \mathrm{C}$ were used to study their effects on anisotropy behavior. The results show that the normal anisotropy value of annealed samples at $1150^{\circ} \mathrm{C}$ increases by (31\%) as compared to the received samples. This indicates that the annealed samples at $1150{ }^{\circ} \mathrm{C}$ have the highest formability. Also, results show significant reduction (about 88.7\%) in planar anisotropy value for $1150^{\circ} \mathrm{C}$ annealed samples. This gave rise to an increase in deep drawing yield.
\end{abstract}

Keywords: anisotropy, annealing treatment, stainless steel 304.

Paper History: Received: (1/11/2016), Accepted: (8/3/2017)

\section{Introduction}

Nowadays, cold-rolled stainless steels sheets have been increasingly utilized in various industries like production of domestic appliances and in automotive industry because of its good formability, excellent strength, and resistance to corrosion. However, because of the microstructural complexities, like the formation of different textures, arising during the rolling of stainless steels and this induce the anisotropic behavior of cold-rolled stainless steel [1, 2]. Preferred grain orientation which forms during rolling processes is the main cause of anisotropy in materials. Anisotropy in the metal leads to inverse effects on subsequent sheet metal forming processes, especially deep drawing operation [3]. Where, directionality in properties and rolled texture usually give rise to excessive earring, tears, and breakout in parts production by deep drawing and extrusion processes. Drawn cups earing are due to vary values of plastic strain ratio at different directions [4]. After deep drawing process, this irregularity (ears) at the top of cups must be eliminated which result in reduce of the process yield and increase in metal waste [5]. Large anisotropic properties lead to higher ear and then reduce in the efficiency of the deep drawing process. Material anisotropy is affected by many factors, grain geometry, rolling conditions, subsequent heat treatment, etc. Many works have been done for evaluation material anisotropy in sheet metal during rolling process.

Soh et. al. [6], optimized some parameters (heat treatment conditions, conditions of plastic deformation (cold work rate, final thickness), the composition of plate, and no. of passes during rolling process) which affected the rolling of aluminum alloy. They show that the anisotropy index can be reduced with increase the thickness of sheets in range from (1.2-2.8) $\mathrm{mm}$. He at el [7], examined the texture of $\mathrm{Mg}-3 \mathrm{Al}-\mathrm{Zn}$ alloy with addition of $3 \%$ wt Li. They found that the introducing specific twins in alloy have an important and effective role on texture modification of alloy during annealing treatment. Tang et al [8], found that the Magnesium AZ31 sheet produced by cross rolling (CR) (process in which the rolling direction was changed by 90o after each rolling pass) has low $r$ value (close to 1) as compared to those produced by conventional unidirectional rolling (UR), which leads to enhancing the drawing capability. Influences of annealing conditions on material anisotropy behavior of $\mathrm{Mg}$ alloy sheets were evaluated by Del Valle and Ruano [9]. They reveal that the thermal treatment lead to noticeable reducing in material anisotropy with grain coarsening. Also, they found that 
the annealing treatment produce a slight change in the basal texture.

Although, there are many works have been done for evaluation material anisotropy in sheet metal during rolling process. However, there have been little efforts focused on evolution the anisotropy behavior of Stainless steels alloys. Stainless steels have high demand on the deep drawing process; however, it shows serious earing in production.

In this study, the effects of annealing treatment on anisotropy parameters of cold-rolled stainless steels 304 sheets were studied. Two annealing temperatures (1050, and 1150$){ }^{\circ} \mathrm{C}$ were used for this purpose. Several uniaxial tensile tests were performed on annealed and as- received samples at different angles $\left(0^{\mathrm{O}}\right.$, $45^{\circ}$ and $90^{\circ}$ ) respect to the rolling direction (RD), to determine the r-value required for this investigation. Anisotropy parameters (normal anisotropy, $r \_n$, and planar anisotropy, $\Delta r$ ) of all samples were measured and compared to identify the optimal conditions which result in minimum earing.

\subsection{Characteristics of Anisotropy}

\subsubsection{Normal Anisotropy}

Many characteristic values are utilized as a measure of material anisotropy. r-value or vertical anisotropy $r$ is the ratio of the logarithmic change of strain in the direction of the sheet width (true width strain) to the change of strain in the direction of the sheet thickness (true thickness strain) [10, 11]:

$$
r=\frac{\operatorname{strain}_{w}}{\operatorname{strain}_{t}}=\frac{\epsilon_{w}}{\epsilon_{t}}
$$

Where $\epsilon_{\mathrm{w}}$ is the strain in the direction of width, and $\epsilon_{\mathrm{t}}$ is the strain in the direction of thickness. Isotropic material has a value of $r=1$. Material that has a $r$-value $>1$, has high resistance to plastic deformation in the direction of the sheet thickness. The r-value is not constant in a sheet plane, but depends on the angle from the rolling direction. The value of vertical anisotropy $r$ is depends also on the previous treatment and the material composition, since the r-values change for the different directions, the average vertical anisotropy (normal anisotropy) $r_{n}$ can be used and calculated $[10,11]$ :

$$
r_{n}=\frac{r_{0}+r_{90}+2 r_{45}}{4}
$$

Where the index indicates the angle to the rolling direction.

The $r_{n}$ value characterizes the sheet resistance to thinning during deep drawing process. The lowest $r_{n}$ value refers to the location in the plane of the sheet with the largest probability of necking. Consequently, $r_{n}$ values are preferred to be as large as possible.

\subsubsection{Planar Anisotropy}

Another important measure for the variance of the r-value over the sheet plane is the planar anisotropy $\Delta \mathrm{r}[10,11]$ :

$$
\Delta r=\frac{r_{0}+r_{90}-2 r_{45}}{2}
$$

The planar anisotropy value has the significant effect on deep drawing process.

The high values of planar anisotropy lead to unfavorable earing during the deep drawing of axially symmetrical cylindrical cups. Otherwise, when planar anisotropy was zero, no earing occurs in the part. Earing is expected in those directions that have the highest $r$ values. Earing takes place in the $90^{\circ}$ and $0^{\circ}$ directions for positive $\Delta r$ values i.e. $(\Delta r>0)$. While, for negative values of $\Delta r$ i.e. $(\Delta \mathrm{r}<0)$, earing takes place at $45^{\circ}$ in respect to rolling orientation.

Generally, for successful deep drawing process, the average vertical anisotropy $r_{n}$ should be as high as possible, whereas the planar anisotropy $\Delta \mathrm{r}$ should be as small as possible.

\section{Materials and Methods}

\subsection{Research Material}

Cold rolled stainless steel 304 sheet with a thickness of $2 \mathrm{~mm}$ was used in this work. The chemical composition of the material is listed in Table 1.

Table 1 Chemical composition of stainless steel 304.

\begin{tabular}{|c|c|c|}
\hline Element & $\begin{array}{c}\text { Measured } \\
\text { Value }\end{array}$ & $\begin{array}{c}\text { Standard } \\
\text { Value }\end{array}$ \\
\hline $\mathbf{C}$ & 0.05 & $\leq 0.08$ \\
\hline $\mathbf{M n}$ & 1.15 & $\leq 2$ \\
\hline $\mathbf{S}$ & 0.027 & $\leq 0.03$ \\
\hline $\mathbf{C r}$ & 18.2 & $18-20$ \\
\hline $\mathbf{N i}$ & 8.6 & $8-12$ \\
\hline $\mathbf{S i}$ & 0.64 & $\leq 0.75$ \\
\hline $\mathbf{N}$ & 0.15 & $\leq 0.12$ \\
\hline $\mathbf{F e}$ & balanced & balanced \\
\hline
\end{tabular}

\subsection{Metallographic Practice}

The metallographic specimens were prepared by mounting, and grinding using emery paper with grit 220 to 1200 in succession. The ground surfaces of the specimens were polished using diamond paste then were etched 
with a solution containing 5 grams of sodium hydroxide $(\mathrm{NaOH})$ dissolved in $100 \mathrm{~mL}$ of water for 20 seconds and then dried. The optical Metallurgical Microscope was used to analyze the microstructure of etched surfaces, and observe the change in grain structure.

\subsection{Heat treatment}

Annealing heat treatments were done on the samples by using muffle furnace. Two annealing temperatures (1050 and 1150) ${ }^{\circ} \mathrm{C}$ were used to heating the samples. The heated samples were soaked for $10 \mathrm{~min}$ and followed by cooling in furnace to room temperature.

\subsection{Tensile test}

The suitability of sheets for deep drawing processes can be evaluated from anisotropy parameters, which are determined from tensile tests. Therefore, experimental tensile tests were conducted and flat specimens with thickness $2 \mathrm{~mm}$ were cut at $0^{\circ}$ and $45^{\circ}$ and $90^{\circ}$ with the rolling directions to be used for measure the r-value of used materials. The test procedure was done according to standard ASTM-E517. The dimension and shape of the sample are shown in Figure 1. The anisotropy coefficient (r-value), normal anisotropy $\left(r_{n}\right)$, and planar anisotropy $(\Delta \mathrm{r})$ can be determined by equations (1-3).

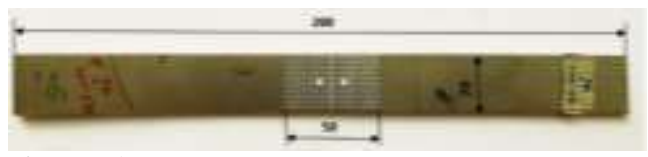

Figure 1: Machined Rectangular Tension Test Specimens, Parallel Strip, for $r$ Determination (all dimension in $\mathrm{mm}$ )

\subsection{Grid application}

Strains to be measured are often very small, and almost the displacement readings are difficult to make with high accuracy. Therefore, a grid was applied on the surface of samples in order to determine strain and displacements components in longitudinal and transverse directions. The dimensions of grid were $(50 \mathrm{~mm} \times 20 \mathrm{~mm})$ and the length between lines was $(1 \mathrm{~mm})$ as shown in Figure 2. A photograph picture was taken of the grid network on all samples. The distance between the grid lines on the model was measured by a microscope by keeping the magnification of microscope same before and after loading.

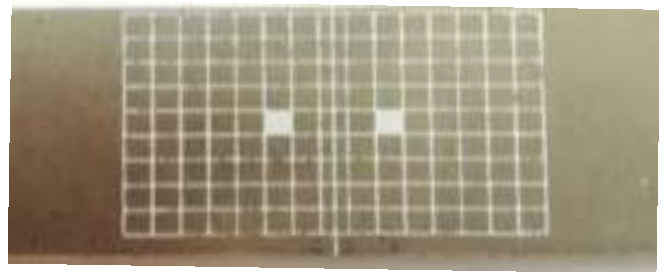

Figure 2: grid for strains and displacements measurement

\section{Results and Discussion}

\subsection{Microstructures}

Figure 3 presents the microstructure of the asrolled and annealing treated stainless steel samples. It is clear from Figure 3 that the microstructure of cold rolled stainless steel 304 samples was modified by heat treatment. For as-rolled case, Figure 3-a, samples have severely deformed microstructure, showing banded structure of grains and inclusions which elongated parallel to the rolling direction. Samples treated at $1050{ }^{\circ} \mathrm{C}$, that illustrate in Figure 3-b, have some deformed grains still remained in addition to small recrystallized grains along boundaries and in most twinned regions. From Figure 3-c, it can be noticed that the full recrystallization is achieved for samples treated at $1150{ }^{\circ} \mathrm{C}$. Also, Figure 3-c indicates that the grain size distribution of sample treated at $1150{ }^{\circ} \mathrm{C}$ become more homogeneous than that in samples treated at $1050{ }^{\circ} \mathrm{C}$. Moreover, the grain size in $1150{ }^{\circ} \mathrm{C}$ treated samples is obviously smaller and more equiaxed compared to treated samples at $1050{ }^{\circ} \mathrm{C}$. it can be concluded from Figure 3 that the microstructure is hardly affected by increasing the annealing temperature, and the high temperature annealing treatment was led to disappear the banded texture and remove the directionality of grains, in spite of some inclusions still remained as in the as-rolled stainless steel samples.

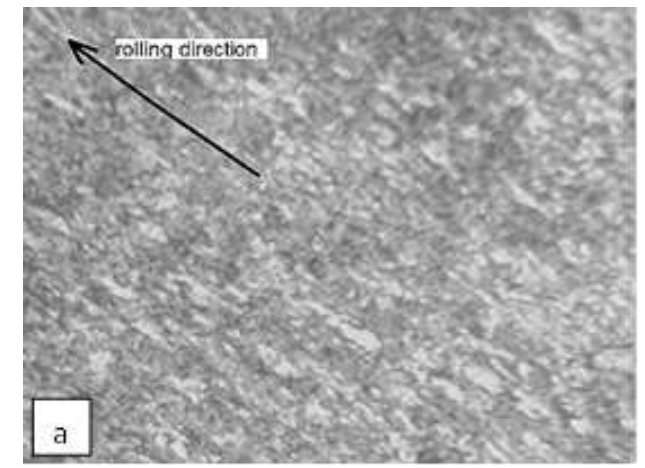



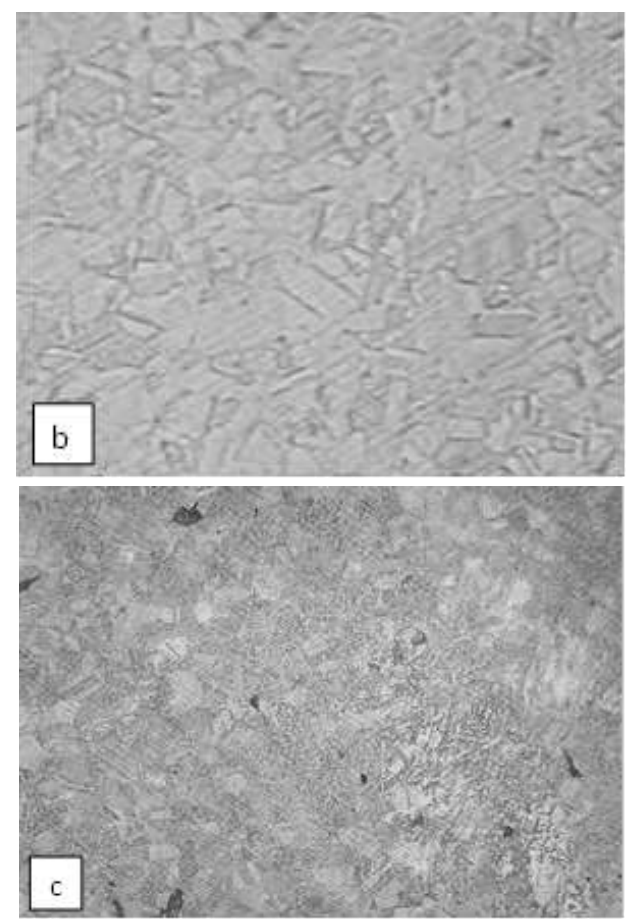

Figure 3: Microstructure of stainless steel samples (a) as rolled (as received); (b) annealed at $1050^{\circ} \mathrm{C}$; (c) annealed at $1150^{\circ} \mathrm{C}$

\subsection{Anisotropy Parameters}

The r-ratio values, normal anisotropy $\left(r_{n}\right)$ and planner anisotropy $(\Delta \mathrm{r})$ of all samples as a function of angle to rolling direction and annealing treatment temperatures are presented in Table 2.

Table 2: Anisotropy parameters for each annealing temperature.

\begin{tabular}{|c|c|c|c|c|c|}
\hline \multirow{2}{*}{ 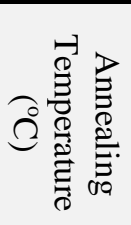 } & \multicolumn{3}{|c|}{$r$-value } & \multirow{2}{*}{ 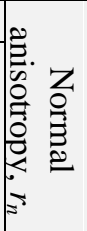 } & \multirow{2}{*}{ 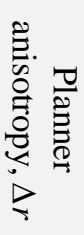 } \\
\hline & O & ज़ & రి & & \\
\hline $\begin{array}{c}\text { As- } \\
\text { received }\end{array}$ & $\begin{array}{l}\circ \\
\stackrel{0}{ } \\
\text { ŭ } \\
\sigma\end{array}$ & $\begin{array}{l}\stackrel{0}{0} \\
\infty \\
\dot{0} \\
u\end{array}$ & 잉 & 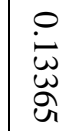 & $\begin{array}{l}\dot{b} \\
\Xi\end{array}$ \\
\hline 1050 & $\begin{array}{l}\stackrel{0}{N} \\
\underset{\infty}{\infty}\end{array}$ & $\begin{array}{l}\underset{\infty}{\infty} \\
\underset{\infty}{\infty}\end{array}$ & $\begin{array}{l}\circ \\
\stackrel{0}{0} \\
\infty \\
\sigma\end{array}$ & $\frac{0}{6}$ & $\begin{array}{l}\dot{0} \\
\dot{0} \\
\stackrel{\mathscr{W}}{\alpha}\end{array}$ \\
\hline 1150 & 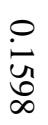 & $\begin{array}{l}0 \\
\stackrel{N}{N} \\
\stackrel{N}{N}\end{array}$ & $\stackrel{0}{\stackrel{0}{\circ}}$ & $\begin{array}{l}\stackrel{0}{v} \\
\text { w } \\
\text { U্ }\end{array}$ & $\begin{array}{l}\dot{0} \\
\dot{0} \\
\text { ర్t }\end{array}$ \\
\hline
\end{tabular}

It can be notice that the values of r-ratio vary somewhat as a function rolling direction angle, this is related to plastic deformation mechanisms which are strongly affected by presence the slip planes, ability of dislocations to move, and presence of inclusions. It is clear from Table 1 that all values of $r_{0}$ and $r_{90}$ in all cases were lower than $r_{45}$. The larger gap between $r_{0}$ and $r_{90}$ as comparison with $r_{45}$, suggest the high values for planar anisotropy and subsequent large waste in metal through deep drawing processes.

Figure 4 shows the effects of anisotropy on yield strength of stainless steel samples under different annealing temperatures. As well known the yield strength is reduced with annealing treatment. It's clear from Fig. 4 that the anisotropy of as received samples and samples annealing at $1050^{\circ} \mathrm{C}$ is more noticeable than that of samples annealing at $1150^{\circ} \mathrm{C}$. For as received samples, the highest value of yield strength was at an angle of 0 and 90 in respect to rolling direction. Whereas, it was at an angle of $0^{\mathrm{O}}$ for $1050^{\circ} \mathrm{C}$ annealed samples. On the other hand, it can be seen from Figure 4 that the directionally properties of $1150^{\circ} \mathrm{C}$ annealed samples was almost removed after annealing treatment. This attributed to disappearance the deformed structure after high annealing temperature and subsequently the directionality of deformed grain was eliminated.

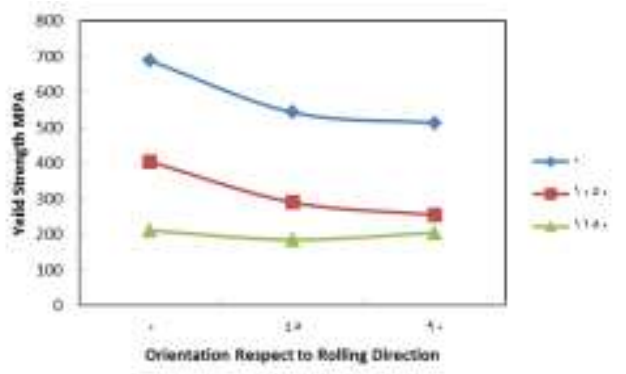

Figure 4: effects of anisotropy on yield strength of stainless steel samples under different annealing temperatures

Figure 5 shows the effects of annealing temperature on normal anisotropy. It can be noticed that the highest value of normal anisotropy occurs for samples annealed at $1150^{\circ} \mathrm{C}$, while the lowest was for as received samples. By recalling Figure 3-c it can be notice that the annealing at higher temperature $\left(1150{ }^{\circ} \mathrm{C}\right)$ yields more fine and homogeneous structure than lower annealing temperature. The increasing in the numbers of refine, rounded and recrystallization grains within microstructure of annealed samples result in reduce the anisotropy effects and enhance the normal anisotropy value that leads to good formality properties. This suggests that normal anisotropy of stainless steel samples strongly correlate with annealing treatment and temperature. It is reported in literatures $[9,10]$ that the annealing and recrystallization treatments play an important role in eliminated 
the anisotropy affects by modification the grain sizes of materials.

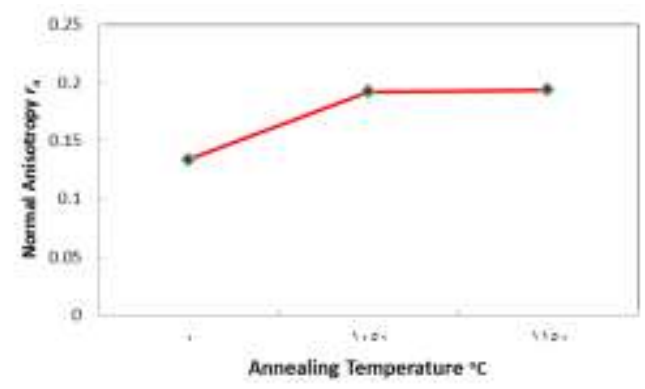

Figure 5: effects of annealing temperature on normal anisotropy

Figure 6 presents the planar anisotropy of as received and annealed stainless steel samples. It follows from Figure 6 that annealing treatment leads to reduce the planar anisotropy value. These results confirmed that the anisotropy depends strongly on the condition under which the samples are deformed and heat treated. Increasing the annealing temperature leads to reduce the disintegration of the recrystallized grains in the samples, thereby, decreasing in planar anisotropy values. This will give rise to an improvement in the deep drawing productivity. The same trend was observed with Tajally and Emadoddin [12] in their research about the evaluation of anisotropy phenomenon of annealed aluminum alloy sheets.

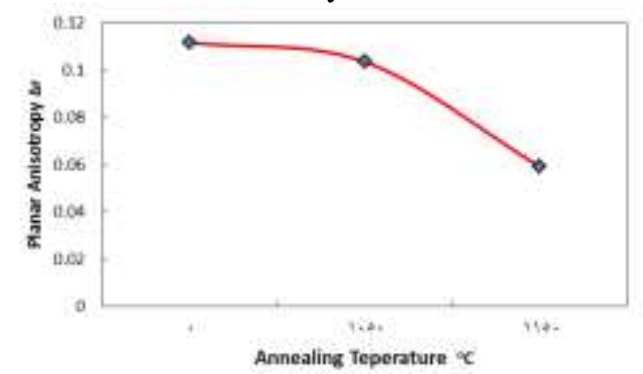

Figure 6: Effects of annealing temperature on planar anisotropy

\section{Conclusion}

It can be concluding from the results of this work: According to the obtained anisotropy parameters results, the waste of cold rolled stainless steel 304 sheets during deep drawing processes can be strongly eliminated by prior heat treatment. The annealing treatment produces a noticeable modification in the basal texture. The annealing treatment leads to an improvement in formability and reduction in anisotropy of cold rolled stainless steel 304 sheets. The annealed temperature $1150^{\circ} \mathrm{C}$ brought the best formability (highest value of normal anisotropy) and lowest anisotropic properties (lower value of planar anisotropy) of cold rolled stainless steel 304 sheets.

\section{References}

[1]. Starman, B., Marko, V., Halilovic, M., and Štok, B., Advanced Modelling of Sheet Metal Forming Considering Anisotropy and Young's Modulus Evolution, Journal of Mechanical Engineering 60, (2), (2014), 84-92.

[2]. Omura, K., Kunioka, S., and Furukawa, M., Product Development on Market Trends of Stainless Steel and Its Future Prospects, Nippon Steel \& Sumikin Stainless Steel Corporation, Technical Report, (99), (2010), 9-19.

[3]. Tajally, M., Emaddodin, E., and Qods, F., An Experimental Study on Earing and Planar Anisotropy of Low Carbon Steel Sheets, World Applied Sciences Journal, 15(1), (2011), 1-4.

[4]. Younis, K., M., and Jaber, A., S., Experimental and Theoretical Study of Square Deep Drawing, Eng. \& Tech. Journal, 29(12), (2011), 2456-2467.

[5]. Chen, C., Y., Kuo, J., C., Chen, H., L., and Hwang, W., S., Experimental Investigation on Earing Behavior of Aluminum/Copper Bimetal Sheet, Materials Transactions, 47, (9), (2006), 2434-2443.

[6]. Fotsing, B., D., Fogue, M., Fomethe, A., Anago, G., F., Nguena, E., and Njimkouo, Y., An industrial Method for Reducing the Anisotropy Index of Aluminium 1200 Rolled Sheets, International Journal of Engineering and Technology, 2, (5), (2010), 365-372.

[7]. He, J., Jiang, B., Yang, Q., Xu, J., Liu, B., and Pan, F., Improved the Anisotropy of Extruded Mg-3Li-3Al-Zn Alloy Sheet by Presetting Grain Re-orientation and Subsequent Annealing, Journal of alloys and compounds, 676, (2016), 64-73.

[8]. Tang, W, Huang, S., Li, D., and Peng, Y., Mechanical Anisotropy and Deep Drawing Behaviors of AZ31 Magnesium Alloy Sheets Produced by Unidirectional and Cross Rollin, Journal of materials processing technology, 215 (2015), 320326.

[9]. Del Valle, J., A., and Ruano, O., A., Effect of Annealing Treatments on the Anisotropy of a Magnesium Alloy Sheet Processed by Severe Rolling, Materials Letters, 63, (17), (2009), 1551-1554.

[10]. Wierzbinski, S., Anisotropy of the Plasticity of Copper Strips After Anisotropic Recrystallization Heat Treatment, Metal Science and Heat Treatment Journal, 27 (7), (1985), 517-521. 
[11]. Al-Saadi, M., H., Ameen, H., A., and AlKalali, R., H., "Influence of Metal Type on the Deep Drawing Force by Experimental and Finite Element Method", Eng. \& Tech. Journal, 29 (13), (2011), 2601-2608.
[12]. Tajally, M., Emadoddin, E., Mechanical and Anisotropic Behaviors of 7075 Aluminum Alloy Sheets, Materials and Design, 32 (3), (2011) 1594-1599. 